\title{
A INOVAÇÃO SUSTENTÁVEL EM INTEGRANTES DO STARTUP CHILE
}

\author{
THE SUSTAINABLE INNOVATION IN STARTUP CHILE COMPANIES
}

Recebido em 05.02.2020 Aprovado em 09.03.2020

Avaliado pelo sistema double blind review

DOI: https://doi.org/10.32888/cge.v8i1.40606

\section{Rodrigo Reis Favarin}

rodrigo.favarin@hotmail.com

Programa de Pós-Graduação em Administração/Universidade Federal de Santa Maria (UFSM) - Santa

Maria/Rio Grande do Sul, Brasil

https://orcid.org/0000-0001-8591-5733

Cristiano Silveira dos Santos

cristianosilveiradossantos@gmail.com

Programa de Pós-Graduação em Administração/(UFSM) - Santa Maria/Rio Grande do Sul, Brasil

https://orcid.org/0000-0003-3544-0586

\section{Isaque Guilhermando Koche}

isaquegk@hotmail.com

Programa de Pós-Graduação em Administração/(UFSM) - Santa Maria/Rio Grande do Sul, Brasil https://orcid.org/0000-0002-1795-5458

\section{Jordana Marques Kneipp}

Jordana.kneipp@ufsm.br

Programa de Pós-Graduação em Administração/(UFSM) - Santa Maria/Rio Grande do Sul, Brasil https://orcid.org/0000-0001-6982-994X

\author{
Marcelo Trevisan \\ marcelotrevisan@smail.ufsm.br \\ Programa de Pós-Graduação em Administração/(UFSM) - Santa Maria/Rio Grande do Sul, Brasil \\ https://orcid.org/0000-0002-2403-7970
}

\section{Resumo}

O presente estudo visa identificar as inovações orientadas para a sustentabilidade em startups do Startup Chile e analisá-las com foco nos elementos do cubo da inovação sustentável de Hansen, Grosse-Dunker e Reichwald (2009). A pesquisa se classifica como qualitativa, utilizando para coleta de dados a pesquisa documental e para análise dos dados, a análise de conteúdo. Em relação aos resultados, é notável a preocupação das empresas em abarcar as três dimensões do triple bottom line no desenvolvimento dos seus produtos e serviços, assim como a maioria dos elementos do cubo da inovação sustentável nas inovações mapeadas.

Palavras-chave: Inovação sustentável. Sustentabilidade. Startups.

\begin{abstract}
The study aims to identify the sustainability-oriented innovations in Startup Chile's startups and analyze them focusing on the elements of the sustainable innovation cube of Hansen, Grosse-Dunker and Reichwald (2009). The research is classified as qualitative, using documentary research for data collection and content analysis for data analysis. Regarding the results, it is notable that companies are concerned with embracing the three dimensions of the triple bottom line in the development of their products and services, as well as most elements of the sustainable innovation cube in mapped innovations.
\end{abstract}

Keywords: Sustainable innovation. Sustainability. Startups. 


\section{Introdução}

A situação da degradação ambiental e da desigualdade social passou a ser discutida globalmente após a realização da Conferência do Meio Ambiente e Humanidade em 1972, na cidade de Estocolmo (VOLKMER, 2014). As responsabilidades pelos prejuízos advindos destas situações são comumente atribuídas às organizações, devido ao impacto gerado pelas suas atividades no meio ambiente e sociedade, elevando o nível de cobrança dos órgãos públicos e consumidores, resultando em mudanças de comportamentos.

Estas mudanças exigiram mais responsabilidade de todos e ações sustentáveis urgentes, obrigando as empresas a se tornarem mais flexíveis e adaptadas às novas demandas de mercado (SANTOS e BAPTISTA, 2016). Uma das formas utilizadas pelas empresas para fazer diferente é por meio da inovação, porém, não na sua forma tradicional, mas com o foco na sustentabilidade.

A inovação sustentável se materializa de diversas maneiras, seja por meio da renovação ou melhoria de produtos, serviços, processos tecnológicos ou organizacionais, estruturas e modelos de negócios em curto e longo prazo, melhorando o desempenho das dimensões econômica, ambiental e social (BOS-BROUWERS, 2010).

Estas três dimensões formam o Triple Bottom Line, termo cunhado por Elkington (1997), expõem que as empresas necessitam contribuir com as dimensões econômica, social e ambiental para que a sustentabilidade seja efetivamente promovida. Com a mesma visão de Elkington, Martens et al (2016) salientam para o fato de que a inovação sustentável também precisa considerar o tripé da sustentabilidade no seu desenvolvimento.

Com o intuito de analisar as inovações sustentáveis, esta investigação tem como foco as startups, definidas por Blank e Dorf (2012) como organizações constituídas para encontrar um modelo de negócio repetível e escalável. Nesse sentido, um país que tem se destacado no cenário da América Latina é o Chile, que por meio do programa Startup Chile atrai startups de diversas áreas de atuação, de todas as partes do mundo, criando um resultado rico em diversidade cultural e impacto local. Além de ajuda financeira, a startup recebe diversas mentorias e é acompanhada por toda sua passagem no programa (STARTUP CHILE, 2018).

Nesse viés, este estudo tem como objetivo geral identificar as inovações orientadas para a sustentabilidade em startups integrantes do portfólio do Startup Chile e analisá-las com foco nos elementos do cubo da inovação sustentável de Hansen, Grosse-Dunker e Reichwald (2009). Como objetivos específicos têm-se (a) mapear e caracterizar as startups que visam desenvolver inovações orientadas para a sustentabilidade no portfólio do Startup Chile; (b) identificar as inovações orientadas para a sustentabilidade trabalhadas pelas empresas (c) relacionar as inovações orientadas para a sustentabilidade identificadas e relacioná-las com os elementos do cubo da inovação sustentável de Hansen, Grosse-Dunker e Reichwald (2009).

Este estudo tem a seguinte estrutura: introdução, revisão de conceitos relacionados à inovação orientada para a sustentabilidade e startups e a inovação orientada para a sustentabilidade, apresentação do método, apresentação e análise dos resultados, considerações finais e referências.

\section{Inovação orientada para a sustentabilidade}

O conceito da sustentabilidade tornou-se amplamente conhecido em diversos campos do conhecimento, o que de certa forma, dificulta a sua compreensão. Em muitos casos seu conceito é relacionado com o desenvolvimento sustentável, embora alguns autores desconsiderem os termos como sinônimos (SEM, 2004; ROBINSON, 2004). A presente investigação abordará os temas sem distinção de significado, conforme o posicionamento de Bellen (2006) e Barbieri e Silva (2011).

Em estudos do campo da Administração, um dos conceitos de desenvolvimento sustentável mais difundidos tem origem na Comissão Mundial sobre Meio Ambiente e Desenvolvimento (1988), que considera o desenvolvimento sustentável como o "desenvolvimento que satisfaz as necessidades do presente sem comprometer as habilidades 
das futuras gerações de satisfazerem suas necessidades" (CMMAD, 1991, p. 44). De um ponto de vista organizacional o tema tem sido exaustivamente investigado por pesquisadores que buscam analisar os diferentes motivos que levam as organizações a implementá-los nas suas operações (VADARAJAN, 2014).

Diversas organizações, em determinados momentos reduzem o termo sustentabilidade à um ato de, por exemplo, fazer um trabalho voluntário ou manter suas indústrias limpas. Elkington critica duramente esse pensamento, sinalizando que sustentabilidade necessita ser analisada de uma maneira global, na qual alterações econômicas e políticas possam ser executadas de maneira a beneficiar sociedade e meio ambiente, através de um novo mercado (FIGUEIREDO; FILHO, 2009).

Com o intuito de auxiliar as organizações promoção da sustentabilidade, ELKINGTON (2011), criou o modelo do Triple Bottom Line - Tripé da Sustentábilidade. Nesta proposta busca-se equilibrar simultaneamente fatores econômicos, sociais e ambientais, de forma a orientar as empresas na efetivação de práticas sustentáveis, além de auxiliar na composição da estratégia empresarial (ELKINGTON, 2001). Figura 1 apresenta o modelo gráfico do Triple Bottom Line.

Figura 1 - Modelo do Triple Bottom Line

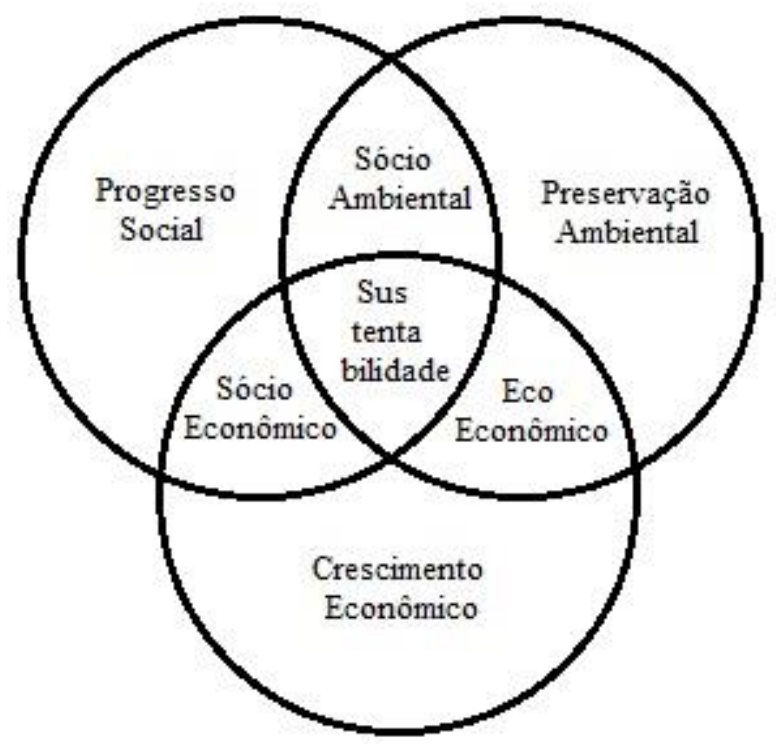

Fonte: Elaborado pelos autores com base em Elkington (2001)

Conforme exposto na Figura 1, as intersecções entre os pilares econômico (crescimento econômico), ambiental (preservação ambiental) e social (progresso social) também correspondem à progressos em busca da sustentabilidade, porém a mesma é efetivamente alcançada, somente quando as empresas compreendem os três pilares em seus esforços (GIMENEZ, SIERRA e RODON, 2012; SANTOS, 2015).

Dias (2012) discorre sobre o que compreende cada dimensão do TBL:

a) Dimensão econômica: envolve o desempenho financeiro tradicional da empresa, mas também a sua capacidade de contribuir com o desenvolvimento econômico local e de todas as partes interessadas de forma ética e responsável (stakeholders);

b) Dimensão ambiental: está relacionada com as atividades da empresa e a proteção dos ecossistemas envolvendo geração de resíduos, consumo de recursos ambientais e emissão de elementos poluidores;

c) Dimensão social: envolve as consequências sociais da atividade da empresa perante o conjunto dos seus stakeholders, tais como as políticas sociais da empresa e os direitos humanos.

As organizações estão buscando a inovação para o desenvolvimento de processos, produtos e serviços que alinhem os objetivos organizacionais com o tripé da sustentabilidade. Porém, Carlomagno e Scherer (2009), atentam para o fato de que a inovação não deve ser vista apenas como o desenvolvimento de um novo produto, mas também, 
como o desenvolvimento de novos modelos de negócio, mercados e serviços, novas formas de gestão, concepção de uma marca, criação de plataformas tecnológicas e, até mesmo, à formação de canais de distribuição.

Deste direcionamento da inovação sendo orientada para a geração de benefícios para a sustentável, surge a inovação sustentável, que pode ser definida como a introdução (produção, assimilação e exploração) de produtos, processos produtivos, métodos de gestão ou negócios, novos ou significativamente melhorados para a organização, e que trazem benefícios econômicos, sociais e ambientais, comparados com alternativas pertinentes (BARBIERI et al, 2010). Logo, observa-se que a inovação orientada para a sustentabilidade atua como uma ferramenta que permite abranger tanto as questões da sustentabilidade, como também, a conquista de novos segmentos de clientes e mercados, consistindo na inovação individualmente percebida por agregar valor positivo para o capital global da firma. (HANSEN, GROSSE-DUNKER E REICHWALD, 2009). Assim, as empresas devem estar atentas para os aspectos de sustentabilidade, pela sua possibilidade de proporcionar a descoberta de novos nichos de mercado, além da ampliação de mercados já atendidos (PORTER; KRAMER, 2006; SANTOS E SILVA, 2016).

Savitz (2007) salienta que o movimento da sustentabilidade transformou o modo como os gestores se relacionam com o meio ambiente e com outras pessoas, dentro e fora da organização e deste advirão consequências ainda mais abrangentes. Numa visão mais ampla, a gestão da inovação sustentável estimula as empresas a aprenderem novas abordagens e a abandonarem antigas práticas, de maneira a envolver novas tecnologias, novos mercados, novas condições ambientais e regulamentações (SEEBODE, JEANRENAUD E BESSANT, 2012). Cutovol (2016) alerta para a complexidade do desafio que as organizações enfrentam ao desenvolverem estratégias sustentáveis, mas que ao obterem êxito neste processo, a gestão da inovação proporciona vantagem competitiva, além de estimular outras empresas com a noção de alcançar um mundo mais social e ambientalmente melhor.

Hansen, Grosse-Dunker e Reichwald (2009) estabeleceram um modelo denominado cubo da inovação sustentável (CIS), constituído de um framework para à inovação que evidencia os efeitos da sustentabilidade em diferentes áreas da organização. Este modelo apresenta elementos considerados importantes para os autores, no tocante às inovações sustentáveis e é apresentado no Quadro 1.

Quadro 1 - Elementos da inovação sustentável segundo modelo do CIS

\begin{tabular}{|l|l|}
\hline \multicolumn{1}{|c|}{ Elementos } & \multicolumn{1}{c|}{ Descrição } \\
\hline $\begin{array}{l}\text { Investigação do ciclo de } \\
\text { vida dos produtos }\end{array}$ & $\begin{array}{l}\text { Averígua-se a origem da matéria-prima, as consequências ambientais e sociais de produção e } \\
\text { consumo e o destino dos produtos no final de sua vida útil. }\end{array}$ \\
\hline $\begin{array}{l}\text { Integração dos critérios de } \\
\text { sustentabilidade }\end{array}$ & $\begin{array}{l}\text { Retrata a necessidade de considerar os impactos econômicos, ambientais e sociais no } \\
\text { desenvolvimento de inovações. Sugere-se equilibrar as três dimensões, prestando maior } \\
\text { atenção aos pilares ambiental e social além do tradicional pilar econômico. }\end{array}$ \\
\hline $\begin{array}{l}\text { Sensibilização no contexto } \\
\text { da sustentabilidade }\end{array}$ & $\begin{array}{l}\text { Significa integrar a sustentabilidade nos processos organizacionais e nos comportamentos por } \\
\text { meio das lideranças para formação de uma cultura favorável à mudança. Ou seja, sensibilizar } \\
\text { os tomadores de decisão envolvidos nos processos de inovação para as questões da } \\
\text { sustentabilidade para que eles possam identificar oportunidades demandadas por stakeholders } \\
\text { e assim diminuir os riscos das inovações. }\end{array}$ \\
\hline Integração dos stakeholders & $\begin{array}{l}\text { Deve haver o estímulo à participação dos stakeholders nos processos de criação de inovações, } \\
\text { de forma que os envolvidos no processo possam avaliar os possíveis impactos sobre a } \\
\text { sociedade e/ou meio ambiente antes mesmo que as novidades sejam lançadas no mercado, e } \\
\text { essa integração pode favorecer o compartilhamento de conhecimentos e inspirar inovações. }\end{array}$ \\
\hline $\begin{array}{l}\text { Incremento do sistema de } \\
\text { produto e serviço }\end{array}$ & $\begin{array}{l}\text { A empresa deve pensar no desenvolvimento de inovações que deslocam o foco empresarial } \\
\text { de vender apenas produtos físicos, de modo que os consumidores comprem a utilidade ou } \\
\text { serviço oferecido pelo produto. As empresas podem agregar uma maior quantidade de } \\
\text { serviços ao longo do ciclo de vida dos produtos, produzir de forma customizada, evitar } \\
\text { desperdícios de recursos, e construir relações de longo prazo com os clientes. }\end{array}$ \\
\hline $\begin{array}{l}\text { Marketing direcionado à } \\
\text { inovação sustentável }\end{array}$ & $\begin{array}{l}\text { Refere-se ao desafio de criar e projetar novas necessidades sustentáveis e alterar o estilo de } \\
\text { vida atual. }\end{array}$ \\
\hline
\end{tabular}

Fonte: Adaptado de Hansen, Grosse-Dunker e Reichwald (2009).

Diversos estudos têm buscado identificar práticas inovadoras sustentáveis nas organizações. Tais práticas podem ser exemplificadas por meio de modificações em produtos e serviços com o propósito de se adequarem às legislações locais, a utilização de materiais com redução do impacto ambiental e a opção de valorizar empresas 
locais na compra de matérias primas (SANTOS et al., 2014; ALMEIDA, 2015). O resultado de práticas relacionadas à colaboração da empresa para inovar, foi averiguado nos estudos de Kuhl et al. (2016) e Macchion et al. (2016) como impactantes positivamente na performance inovadora das empresas. Santos e Silva (2016) investigaram como a sustentabilidade e a inovação contribuem para as organizações, e também os desafios e oportunidades para as empresas que desenvolvem práticas inovadoras sustentáveis. Os autores concluíram que o atual ambiente competitivo exige que as organizações aliem a inovação e a sustentabilidade para irem além das expectativas endógenas da empresa.

Trifilova et al (2013) afirma que embora muitas empresas utilizem a inovação orientada para a sustentabilidade com o objetivo de cumprir ações regulatórias, há também um segmento considerável e crescente de organizações que procuram assumir uma postura proativa de identificação e exploração de novas oportunidades. Este segmento inclui o empreendedorismo de startups e também de grandes corporações, que alteram os seus modelos de negócios.

Hansen e Grosse-Dunker (2013) evidenciam que os conceitos de ecoempreendedorismo, empreendedorismo social e empreendedorismo sustentável denotam a importância de novas empresas e startups para estimular o desenvolvimento sustentável através dos mecanismos de "desconstrução criativa" de Schumpeter (1982).

À medida que as empresas se tornam mais adeptas a novas alternativas, a experiência levará as mesmas ao estágio final de inovação sustentável, onde o impacto de um novo produto ou processo se estende para além de um mercado único (NIDUMOLU, 2009). Martens et al (2016) salientam para o fato de que a inovação sustentável precisa levar em conta o tripé da sustentabilidade, ou seja, as variáveis econômicas, ambientais e sociais, conforme será exposto na próxima seção. Nesta seção foram abordados estudos de organizações já consolidadas que buscam alinhar a sustentabilidade aos seus negócios. A seção a seguir, além de tratar das startups, também abordará a implementação de inovações sustentáveis desde a concepção dos negócios.

\section{Startups e a inovação orientada para a sustentabilidade}

As startups são definidas como organizações construídas para encontrar um modelo de negócios repetível e escalável (BLANK; DORF, 2012). Colaborando com a definição acerca do tema, Ries (2012) afirma que as startups são instituições humanas designadas a entregar um produto ou serviço sob condições de extrema incerteza. No mercado contemporâneo, as startups têm sido protagonistas de mudanças, com negócios criados a menos de uma década, mas que figuram entre as empresas mais valiosas do mundo. Segundo Weiblen e Chesbrough (2015), startups são mais ágeis em inovar, sendo este ponto uma vantagem competitiva sobre as grandes corporações.

Nesta nova ordem da economia global, na qual se busca, segundo Porter (2004), baixo custo, diferenciação e foco, a estratégia competitiva vem determinando a velocidade do crescimento e posicionamento das startups no mercado. Para Da Silva et al (2013) o foco destes tipos de empresas está direcionado no processo de inovação, no qual na maioria dos casos os empreendedores iniciantes buscam a sua inserção em incubadoras tecnológicas. As novas tecnologias proporcionam às startups a capacidade de desafiar a sabedoria convencional e que, diferentemente das formas atuais, desenvolver um novo modelo de negócio requer a exploração de alternativas (NIDUMOLU, 2009).

O crescimento constante da competitividade na escala mundial vem influenciando gradativamente o comportamento das empresas, exigindo das mesmas estratégias diferenciadas para se posicionarem em outros mercados. Essas estratégias, muitas vezes, se relacionam diretamente a fatores facilitadores para acesso a esses mercados, como infraestrutura adequada, acesso a recursos financeiros e acesso à informações de mentores (PORTER, 2004). A Tabela 1 apresenta o valor investido por meio de instituições aceleradoras de empresas juntamente com o número de startups de cada localidade. 
Tabela 1 - Valor investido por meio de aceleradoras de empresas

\begin{tabular}{ccc}
\hline Região & Total investido (US\$) & Número de startups \\
\hline Estados Unidos e Canadá & 90.295 .774 & 2968 \\
Europa & 41.007 .000 & 2574 \\
América Latina & 31.563 .841 & 1333 \\
Ásia e Oceania & 16.842 .427 & 1295 \\
Oriente Médio & 12.290 .715 & 666 \\
\hline Total & 191.999 .757 & 8836 \\
\hline
\end{tabular}

Fonte: Global Accelerator Report 2015

$\mathrm{Na}$ América Latina, o Brasil e Chile têm se destacado dos demais países pelo desenvolvimento de fortes programas de investimentos em startups, como o programa do governo chileno denominado Startup Chile, o qual busca atrair empreendedores do mundo todo, com financiamento de US $\$ 40.000,00$ para que a startup desenvolva seu negócio na capital do país (GLOBAL ACCELERATOR REPORT, 2015).

Torna-se importante salientar que o Chile, país promotor do programa Startup Chile que integra as empresas startups analisadas neste estudo, está posicionado em primeiro lugar no ranking de investimentos por aceleradoras de empresas na América Latina (Tabela 1), com US\$ 15.096.929,00 investidos em 442 startups. Este volume é fruto do esforço do governo chileno, que por meio do Startup Chile, busca impulsionar a atividade produtiva nacional, atraindo empreendedores com alto potencial, que possuam empresas em estágios iniciais, mas que tenham potencial para se tornarem globais (QUINTAIROS, ALMEIDA E OLIVEIRA, 2013).

O principal objetivo do programa Startup Chile é converter o país em um centro de inovação e empreendedorismo da América Latina. Além do financiamento, o programa oferece visto de um ano para os empreendedores selecionados, acesso a escritórios compartilhados e a possibilidade de receber auxílio de mentores (MANDAKOVIC, COHEN e AMORÓS, 2015).

Com relação a inovação e as startups, Ionica e Leba (2016) afirmam que a inovação é a palavra que melhor descreve o mundo das startups, no qual as novas ideias e o trabalho criativo unem pessoas entusiasmadas, advindas de diferentes lugares, para o desenvolvimento de novos produtos. Estes produtos e serviços, estão sendo cada vez mais orientados para a promoção da sustentabilidade. As startups que desejam agregar valor aos seus produtos ou serviços, devem incorporar o Tripé da sustentabilidade em suas inovações (Weissbrod \& Bocken, 2016).

Segundo Rodgers (2010), frequentemente a sustentabilidade é pensada como um privilégio de grandes organizações, as quais possuem recursos para investir em qualquer coisa que seja efetivamente verde para reduzir a sua pegada de carbono. Algo que é menos entendido e documentado são as atitudes tomadas por pequenas e médias empresas, incluindo pequenas startups, que inclusive baseiam o seu modelo de negócios em princípios sustentáveis (Rodgers, 2010).

\section{Procedimentos metodológicos}

Para atingir o objetivo proposto, foi desenvolvida uma pesquisa que se caracteriza, quanto à sua abordagem, como qualitativa. Para Richardson (1999), as investigações que se voltam para uma análise qualitativa têm como objeto situações complexas ou estritamente particulares. Segundo Godoy (1995), um fenômeno pode ser mais bem compreendido, nos estudos qualitativos, pois ele está inserido no contexto onde ocorre e do qual é parte, sendo analisado em uma perspectiva integrada.

Quanto à natureza da pesquisa, classifica-se como descritiva, que visa a identificar, descrever e analisar as práticas inovadoras sustentáveis das empresas estudadas. Para Triviños (1987), este tipo de estudo pretende descrever os fatos e fenômenos de determinada realidade. 
O estudo investigou quatro startups que participaram do programa Startup Chile e que estão presentes em seu portfólio online. As empresas foram selecionadas por apresentarem relações com a sustentabilidade em seus negócios. O programa Startup Chile possui em seu portfólio do website 336 startups e, dentre estas, realizou-se a pesquisa no filtro de busca pela palavra "sustentável" e obteve-se como resultado, quatro empresas: Têm Açúcar?, VECZO, eBatuta e Bureo. O período de análise foi entre maio a julho de 2017.

A coleta de dados foi realizada por meio de pesquisa documental nos websites das empresas e de reportagens que foram divulgadas a respeito das mesmas. Os dados foram analisados de forma descritiva com o intuito de evidenciar a relação entre as inovações orientadas para a sustentabilidade identificadas e o cubo da inovação sustentável de Hansen, Grosse-Dunker e Reichwald (2009) que contém os elementos: investigação do ciclo de vida dos produtos; integração dos critérios de sustentabilidade; sensibilização no contexto da sustentabilidade; integração dos stakeholders; incremento do sistema de produto e serviço; e marketing direcionado à inovação sustentável.

\section{Apresentação e análise dos resultados}

Para a análise dos resultados, primeiramente buscou-se a caracterização das empresas, para que posteriormente fossem identificadas as práticas inovadoras orientadas para a sustentabilidade. Ao final, as práticas identificadas foram relacionadas com as dimensões do Triple Bottom Line e com os elementos do cubo da inovação sustentável.

\section{Caracterização das empresas}

A empresa Tem Açúcar é um website que busca facilitar o cotidiano de pessoas que moram próximas. Trata-se de uma plataforma que possibilita empréstimos de objetos em uma vizinhança, com o objetivo de estimular a colaboração, o companheirismo e o senso de comunidade entre as pessoas (TEM AÇÚCAR, 2017).

A plataforma foi idealizada pela estudante de comunicação carioca Camila Carvalho e é gratuita. O site procura resgatar o antigo hábito de bater na porta do vizinho para pedir "uma xícara de açúcar". A partir desse antigo hábito foi concebido o nome da startup (TEM AÇÚCAR, 2017).

A startup Veczo foi fundada por Luis Beltrán Cardozo Biaggi e Limal Gerardo Cadagan. A empresa se concentra no desenvolvimento de produtos de ortopedia, serviços de impressão de fibra de carbono em 3D, sistemas sustentáveis e gerenciamento de projetos destinados à América Latina (VECZO, 2017).

A startup possui um projeto voltado para o desenvolvimento de próteses biônicas e dispositivos de mobilidade com estruturas de fibra de carbono e vidro. O seu objetivo é oferecer aos indivíduos que sofreram amputações ou possuem algum problema de mobilidade, próteses personalizadas que proporcionem uma condição de vida normal e de pleno alcance do potencial físico (VECZO, 2017).

A empresa eBatuta possui como objetivo principal unir os turistas com os artesãos locais, de modo que os turistas possam adquirir lembranças autênticas do país visitado, por meio do website ou do aplicativo móvel, contribuindo com as comunidades artesãs locais. Seus co-fundadores são Faiza, empreendedora social do Marrocos, com ampla experiência em micro finanças e trabalho de desenvolvimento no campo (México e Sri Lanka), trabalhando em estreita colaboração com os artesãos, e Emmanuel, engenheiro de telecomunicações francês, que possui ampla experiência em Engenharia, TI e Desenvolvimento de Negócios na América Latina, Ásia e Europa (EBATUTA, 2017).

De acordo com a Faiza, esta homenagem representa o esforço para conectar os viajantes à procura de uma lembrança ou presente autêntico feito localmente, com artesãos que produzem artesanatos de alta qualidade em todo o mundo. Ao fornecer essa conexão, eles acreditam firmemente que isso contribuirá para o desenvolvimento da comunidade, especialmente nas áreas rurais, aumentando a renda do artesão e desenvolvendo vínculos comerciais sustentáveis entre produtores de artesanato e mercados de turismo (EBATUTA, 2017). 
A empresa Bureo possui como objetivo principal reduzir a poluição dos oceanos, por meio da retirada de redes de pesca do fundo do mar para transformá-las em produtos comercializáveis. Segundo informações do seu site, os fundadores têm como missão encontrar soluções inovadoras para evitar o acúmulo de resíduos plásticos oceânicos. A sua equipe compartilha paixão pelo surf e pela saúde do meio ambiente (BUREO, 2017).

A startup explica que o nome Bureo vem da língua mapúche, dos chilenos nativos, e significa “ondas", em alusão às mudanças que querem provocar. Seus principais produtos são os skates, porém a empresa já está expandindo o seu portfólio, com a produção de óculos de sol e realizando testes para novos produtos (BUREO, 2017). Para findar esta seção, o Quadro 2 apresenta informações como, o ano de início da atividade de cada empresa, bem como país sede e os seus fundadores.

Quadro 2 - Informações sobre as empresas analisadas

\begin{tabular}{|c|c|c|c|c|}
\hline & Tem Açúcar & Veczo & eBatuta & Bureo \\
\hline Início das atividades & 2014 & 2015 & 2013 & 2012 \\
\hline País & Brasil & Chile & França & Estados Unidos \\
\hline Fundadores & Camila Carvalho & $\begin{array}{c}\text { Luis Beltrán } \\
\text { Cardozo }\end{array}$ & Faiza HAJJ & David Stover \\
\cline { 2 - 5 } & & $\begin{array}{c}\text { Limal Gerardo } \\
\text { Cardozo }\end{array}$ & Emmanuel Wozniak & Ben Kneppers \\
\cline { 2 - 5 } & & & & Kevin Ahearn \\
\hline
\end{tabular}

Fonte: Elaborado pelos autores.

A próxima seção abordará as práticas inovadoras orientadas para a sustentabilidade identificadas nas empresas.

\section{Práticas inovadoras orientadas para a sustentabilidade identificadas}

A principal prática inovadora identificada na startup Tem Açúcar é a possibilidade de difusão de um consumo mais consciente da população e, por meio de uma plataforma web, alertar o consumidor para evitar compras desnecessárias. Para a fundadora da empresa, "nosso objetivo é de realocar recursos que existem muitas vezes ociosos, passando de onde eles são abundantes para onde são escassos” (ÉPOCA NEGÓCIOS, 2015, p. 01). A inovação da empresa vai ao encontro do exposto por Trifilova et al (2013), que discorre sobre a postura proativa de certas empresas ao identificarem e explorarem novas oportunidades de negócios.

Para Carvalho, o planeta não aguenta o atual volume de produção, no qual são gastos muitos recursos como matéria-prima e energia com o transporte e produção de produtos. A partir disto, torna-se fundamental identificar o que de fato é necessário, no ato da compra. Além disso, o website busca trazer de volta o "sentimento de comunidade", deixado de lado em cidades grandes. A startup oferece uma solução simples e sem custo para boa parte das necessidades do cotidiano através de uma rede colaborativa de ajuda recíproca e mútua, despertando uma sensação de interdependência entre os vizinhos e aproximando as pessoas (ÉPOCA NEGÓCIOS, 2015).

No website, o usuário informa o seu bairro e a descrição do objeto que precisa. O website envia essa solicitação aos vizinhos e, caso alguém tenha o item requisitado, a mensagem é respondida com as condições de uso, datas de empréstimo e devolução e também com o local de encontro. Depois que o objetivo é devolvido, os usuários avaliam-se mutuamente para aumentar a credibilidade, tanto de quem empresta, quanto de quem pediu emprestado (TEM AÇÚCAR, 2017).

A inovação da startup Veczo está justamente no fato da empresa optar por não comercializar as próteses como um produto, mas sim por meio de um serviço que inclui a prótese, a sua manutenção e atualização, optando e seguindo o modelo da economia circular, que visa a redução dos insumos e produção de resíduos. Por meio do serviço oferecido, a empresa amplia a possibilidade de atuação no mercado em comparação ao oferecido pelas outras organizações (PORTER; KRAMER, 2006; SANTOS E SILVA, 2016)

Por meio da mensalidade, o usuário recebe a unidade, serviço e todas as atualizações que surgem ao longo do período de vigência do contrato. Após a conclusão, o usuário pode renovar ou retornar a prótese para desarmar e

ISSN 2318-9231

CGE | Rio de Janeiro | v. 8 | n. 1 | jan. - abr. 2020 
reciclar seus componentes em novas próteses. De acordo com Biaggi Cardozo, sócio-fundador da empresa, por se tratar de um empréstimo, o valor do produto/serviço chega ao consumidor final de uma forma acessível, diferentemente do modelo atual de próteses, nos quais são consumidos majoritariamente por classes com alto poder aquisitivo (VECZO, 2017).

Outra inovação que a startup chilena oferece é a personalização, ou seja, cada usuário recebe os ajustes apropriados para a sua prótese, melhorando sua performance física e seus movimentos cotidianos. Denominado Lázaro, este projeto muito avançado de prótese biônica visa a oferecer não só um objeto sofisticado, mas um serviço que permite mudar, melhorar e adaptar continuamente o membro artificial de acordo com as necessidades específicas do usuário. Outro atrativo é o valor do produto, que torna-se acessível para o consumidor, por meio da utilização da impressora 3D (EL DEFINIDO, 2017). Seebode, Jeanrenaud e Bessant (2012) evidenciam o fato da inovação sustentável estimular a utilização de novas tecnologias em produtos e serviços, o que corresponde ao executado pela Veczo.

Com relação a empresa eBatuta, a principal prática inovadora orientada para a sustentabilidade identificada foi a criação de um modelo de negócios, por meio do site ou aplicativo de celular, que busca conectar viajantes à procura de uma lembrança autêntica fabricada localmente, e artesãos que produzem artesanato de alta qualidade em todo o mundo. A prática da valorização de produtos locais, em detrimentos de produtos advindos de outras localidades, é citado por Santos et al (2014) e Almeida (2015) como um importante fator da inovação sustentável.

Segundo informações do website da empresa, o eBatuta permite que os artesãos atinjam o público internacional através de dois canais distintos: primeiro os turistas usam o site/aplicativo para encontrar artesãos locais no país que estão viajando e. em segundo lugar, empreendedores sociais podem se inscrever para tornarem-se "Embaixadores" e importarem produtos artesanais para venda em seus mercados locais. O eBatuta atua como uma porta de entrada para facilitar a relação entre comprador e artesão (EBATUTA, 2018).

O objetivo do eBatuta é manter mais dinheiro com a venda de produtos artesanais nas mãos dos artesãos. A fundadora da empresa, em entrevista dada ao portal The Sedge, afirma que as réplicas de fabricação de produtos artesanais em massa feitos à mão inundam muitas áreas turísticas tradicionais em todo o mundo. Isso está desviando os fluxos de receita tradicionais que impulsionam as economias locais. A iniciativa também apoia a utilização de insumos que não degradem o meio ambiente. (THE SEDGE, 2018).

Em relação à última empresa analisada, a Bureo, foi possível verificar um variado conjunto de práticas inovadoras voltadas para a sustentabilidade que foram desenvolvidas pela empresa. Ela demonstra inovação em seus produtos, processo de fabricação, programas para obtenção de matéria-prima e programas de educação. Para a definição do objetivo de trabalho da empresa, os sócios focalizaram no problema da poluição que os plásticos produzem nos oceanos. E a partir dos plásticos, a empresa se concentrou nas redes de pesca, que representam $10 \%$ da poluição desses resíduos plásticos nos oceanos (BUREO, 2017).

Para a execução das atividades da Bureo no Chile, um dos fundadores da empresa trabalha no campo supervisionando a Net Positiva, o programa de reciclagem que é a base da startup Bureo. Por meio da Net Positiva, a coleta de redes descartadas é gerenciada para que se obtenham as matérias-primas necessárias para a fabricação dos produtos, ao mesmo tempo em que reduzem a poluição plasmática dos oceanos.

Uma vez recolhidas, as redes são lavadas e preparadas para um processo de reciclagem mecânico. Dentro deste processo, elas são trituradas, derretidas e cortadas em pequenos grânulos reciclados. Estes pellets são então injetados em moldes de aço para formar os produtos. Carlomagno e Scherer (2009) atentam sobre o fato da inovação sustentável possibilitar a concepção de novos modelos de negócios e produtos, o que impacta positivamente na atuação da empresa.

A startup conta com três diferentes produtos que são fabricados por meio da reciclagem das redes de pesca: skate, óculos de sol e também o frisbee. O skate, denominado $A b i$ na sua última versão, foi o primeiro produto trabalhado pela empresa e ainda se caracteriza como o principal produto. Estima-se que 4,64 metros quadrados de redes de pesca são utilizados para a sua fabricação. As rodinhas do produto são chamadas de ECOthane e são fabricadas a partir de uma fórmula única que incorpora óleo de soja para compensar a dependência de uretano à base de 
petróleo. O frisbee, último produto divulgado, que foi lançado em parceria com o cantor Jack Johnson, o qual também mantém uma forte preocupação com as questões ambientais do planeta, marca o primeiro lançamento dos materiais NetPlus da Bureo, uma iniciativa crescente para mostrar novas capacidades de reciclagem e parcerias para utilizar redes de pesca recicladas (BUREO, 2017).

A startup também atua com programas que oferecem educação aos jovens no Chile e na América do Norte, educando-os de maneira que eles entendam como eles podem fazer parte do movimento para oceanos mais limpos. No Chile, o co-fundador do Bureo, Ben Kneppers, trabalhou diretamente com as ONGs locais e a comunidade para implementar projetos sustentáveis financiados pela Net Positiva. Trabalhando com as maiores empresas de pesca e com os pequenos sindicatos de pesca artesanal, por cada quilo de material coletado através da Net Positiva, a empresa realiza uma doação voltada para o desenvolvimento sustentável nas comunidades em que trabalham, possibilitando ainda mais impactos positivos (BUREO, 2017). Os projetos estão representados no Quadro 3.

Quadro 3 - Programas da Bureo

\begin{tabular}{|c|c|}
\hline Programa & Descrição \\
\hline $\begin{array}{l}\text { Programa de educação } \\
\text { ambiental e centro de } \\
\text { reciclagem da escola }\end{array}$ & $\begin{array}{l}\text { Programa pós-escolar na escola primária de Cocholgüe, onde os facilitadores da } \\
\text { Fundación el Árbo ensinam aos alunos sobre reciclagem e meio ambiente. }\end{array}$ \\
\hline $\begin{array}{l}\text { Programa comunitário de } \\
\text { compostagem - Coleta } \\
\text { Cocholgüe }\end{array}$ & $\begin{array}{l}\text { Um programa comunitário de compostagem que é liderado pelas mulheres locais } \\
\text { de Cocholguë após o desperdício de alimentos ter sido identificado como um } \\
\text { problema na área. }\end{array}$ \\
\hline $\begin{array}{l}\text { Workshops de Capacitação para } \\
\text { o Sindicato de Reciclagem de } \\
\text { Mulheres Lo Roja }\end{array}$ & $\begin{array}{l}\text { Série de oficinas sobre capacitação para todos os sindicatos de reciclagem feminina } \\
\text { em Caleta Lo Roja. Mais de } 30 \text { mulheres participaram do treinamento para educá-las } \\
\text { sobre como aumentar suas operações de reciclagem em toda a comunidade. }\end{array}$ \\
\hline $\begin{array}{l}\text { Melhorias no gerenciamento } \\
\text { de resíduos em Caleta Chipana }\end{array}$ & $\begin{array}{l}\text { Trabalho com a ONG Desierto de Atacama no norte do Chile, para melhorar o sistema } \\
\text { de gerenciamento de resíduos na área. }\end{array}$ \\
\hline $\begin{array}{l}\text { Treinamento de Artesanato } \\
\text { Artesanal para Deficientes }\end{array}$ & $\begin{array}{l}\text { Fundos das coleções líquidas locais são doados para a APANDI, uma organização } \\
\text { sem fins lucrativos local que treina pessoas com deficiência em artesanato. }\end{array}$ \\
\hline
\end{tabular}

Fonte: Elaborado pelos autores

A próxima seção tem o objetivo de relacionar as práticas inovadores orientadas para a sustentabilidade identificadas nas quatro startups, com os elementos do cubo da inovação sustentável.

\section{Elementos do cubo da inovação sustentável}

O Quadro 5 apresenta a relação entre os elementos do cubo da inovação sustentável e as inovações identificadas nas empresas. Foram utilizados três termos no preenchimento do quadro: em parte (quando a inovação da organização se identifica parcialmente com o elemento); sim (quando há a identificação do elemento na inovação da organização) e; não identificado (quando não foi possível identificar o elemento na inovação da organização).

Quadro 5 - Presença dos elementos do cubo da inovação sustentável nas inovações sustentáveis

\begin{tabular}{|c|c|c|c|c|}
\hline \multirow{2}{*}{$\begin{array}{l}\text { Elementos do cubo da inovação } \\
\text { sustentável }\end{array}$} & \multicolumn{4}{|c|}{ Startup } \\
\hline & Tem Açúcar & Ebatuta & Veczo & Bureo \\
\hline $\begin{array}{l}\text { Investigação do ciclo de vida dos } \\
\text { produtos }\end{array}$ & Em parte & Em parte & Em parte & Em parte \\
\hline $\begin{array}{l}\text { Integração dos critérios de } \\
\text { sustentabilidade }\end{array}$ & Sim & $\operatorname{Sim}$ & Sim & Sim \\
\hline $\begin{array}{l}\text { Sensibilização no contexto da } \\
\text { sustentabilidade }\end{array}$ & Sim & $\operatorname{Sim}$ & Sim & Sim \\
\hline Integração dos stakeholders & Não identificado & Não identificado & $\begin{array}{c}\text { Não } \\
\text { identificado }\end{array}$ & $\begin{array}{c}\text { Não } \\
\text { identificado }\end{array}$ \\
\hline $\begin{array}{l}\text { Incremento do sistema de produto e } \\
\text { serviço }\end{array}$ & Sim & Não identificado & Sim & $\begin{array}{c}\text { Não } \\
\text { identificado }\end{array}$ \\
\hline $\begin{array}{l}\text { Marketing direcionado à inovação } \\
\text { sustentável }\end{array}$ & Sim & $\operatorname{Sim}$ & Sim & Sim \\
\hline
\end{tabular}

Fonte: Elaborado pelos autores 
Em relação ao primeiro elemento, relacionado com a investigação do ciclo de vida dos produtos, percebe-se que as quatro empresas o consideram parcialmente. A Tem Açúcar tem o foco no uso, buscando uma maximização da utilização dos produtos que as pessoas possuem em suas casas. A Ebatuta possui relação com a extração de matérias primas e com a comercialização dos produtos, no qual busca conscientizar os artesões a utilizarem recursos que não degradem o meio ambiente. A Veczo preocupa-se com fabricação, uso, manutenção e descarte, para a utilização das peças em outros produtos. Por fim, a Bureo tem relação com a extração de matéria prima e fabricação dos seus produtos, oriundos de redes de pesca recicladas.

O elemento integração dos critérios de sustentabilidade pode ser identificado nas quatro empresas. O Quadro 6 evidencia que as empresas levam em consideração os aspectos ambientais e sociais além do econômico, no desenvolvimento das suas atividades.

Quadro 6- Práticas inovadoras e as dimensões do Triple Bottom Line

\begin{tabular}{|l|l|l|l|}
\hline \multirow{2}{*}{ Startup } & \multicolumn{3}{|c|}{ Eimensões do TBL } \\
\cline { 2 - 5 } $\begin{array}{l}\text { Têm } \\
\text { Açúcar }\end{array}$ & $\begin{array}{l}\text { Econômica } \\
\text { Econia financeira por parte } \\
\text { dos consumidores, e modelo de } \\
\text { negócio que gera renda para a } \\
\text { organização. }\end{array}$ & $\begin{array}{l}\text { Menos recursos são utilizados } \\
\text { com a redução do consumo e } \\
\text { possibilidade do empréstimo. }\end{array}$ & $\begin{array}{l}\text { Desenvolvimento de laços de } \\
\text { amizades entre vizinhos. }\end{array}$ \\
\hline Veczo & $\begin{array}{l}\text { Economia na aquisição de } \\
\text { próteses e geração de renda para } \\
\text { empresa. }\end{array}$ & $\begin{array}{l}\text { Reutilização de peças, o que } \\
\text { gera menor impacto no meio } \\
\text { ambiente. }\end{array}$ & $\begin{array}{l}\text { Possibilidade de que as pessoas } \\
\text { melhorem a sua condição de } \\
\text { vida, a partir da utilização dos } \\
\text { produtos. }\end{array}$ \\
\hline Ebatuta & $\begin{array}{l}\text { Geração de renda para os } \\
\text { artesãos locais } \\
\text { empreendedores. }\end{array}$ & $\begin{array}{l}\text { Apoio de utilização de materiais } \\
\text { que não degradem o meio } \\
\text { ambiente. }\end{array}$ & $\begin{array}{l}\text { Melhoria nas condições dos } \\
\text { artesãos. }\end{array}$ \\
\hline Bureo & $\begin{array}{l}\text { Geração de recursos financeiros } \\
\text { para a empresa com a a } \\
\text { comercialização dos produtos. }\end{array}$ & $\begin{array}{l}\text { Redução de poluição ambiental, } \\
\text { com a retirada das redes de } \\
\text { pesca dos oceanos. }\end{array}$ & $\begin{array}{l}\text { Possibilidade } \\
\text { desenvolvimento } \\
\text { envolvidos nos programas. }\end{array}$ \\
\hline
\end{tabular}

Fonte: Elaborado pelos autores

Conforme apresentado no Quadro 6, a dimensão econômica se refere a possibilidade que os modelos de negócios desenvolvidos oferecem para a geração de renda para as empresas, oferecendo também vantagens para o público, como por exemplo, nos casos da Têm Açúcar e Veczo. No que diz respeito a variável ambiental, ambos os negócios buscam gerar benefícios para o meio-ambiente, seja na redução do uso de matéria-prima, na utilização de materiais que não tragam malefícios para o meio-ambiente, como também no cuidado com a poluição ambiental. Em relação a dimensão social, as quatro empresas trabalham pensando no bem-estar das pessoas, cada uma da sua forma. Seja ao possibilitar o desenvolvimento de relações de amizade entre as pessoas, melhorando a condição de vida de artesões, trazendo esperança de que as pessoas tenham uma vida melhor por meio da utilização de próteses, e também promovendo o desenvolvimento de comunidades. Os achados vão ao encontro dos expostos por Martens et al (2016), que evidenciam a importância de se pensar nas três dimensões do triple bottom line para a efetiva promoção da sustentabilidade.

O terceiro elemento, sensibilização no contexto da sustentabilidade mostrou-se presente dentro das organizações, de acordo com a pesquisa realizada. A empresa Têm Açúcar surgiu da experiência da sócia proprietária ao trabalhar em países em que o trabalho escravo e outros aspectos advindos do consumismo exagerado eram realizados. O Ebatura surgiu da experiência da fundadora em trabalhar com microfinanças e auxílio aos artesões locais. A Veczo surgiu depois que o fundador da empresa desenvolveu uma prótese para um amigo, e sentiu-se movido com as condições que o produto desenvolvido poderia trazer em benefício à mobilidade das pessoas. A Bureo surgiu da comoção dos sócios em relação à quantidade de resíduos nos oceanos. O trio praticava o surfe e almejou contribuir para a redução do problema.

O quarto elemento não foi identificado no estudo realizado. O quinto elemento, referente ao sistema de produto e serviço foi identificado na empresa Têm Açúcar, que desenvolve sua plataforma para que as pessoas realizem o 
empréstimo de objetos, ao invés da aquisição de novos produtos, e a Veczo que estabelece um contrato de aluguel das próteses em oposição à venda dos produtos.

O último elemento, marketing direcionado à inovação sustentável, foi identificado nas quatro organizações, pelo fato de que elas buscam alterar o estilo de vida atual da sociedade. Seja pelo incentivo do empréstimo, do consumo do artesanato local como também do desenvolvimento de produtos que tenham algo a contribuir com a redução da poluição e utilização irresponsável de recursos.

\section{Considerações finais}

O programa Startup Chile atrai para o país startups de diversas áreas de atuação, de todas as partes do mundo, criando um resultado rico em diversidade cultural e impacto local. Neste conjunto de empresas, foi possível identificar quatro organizações que possuem alguma relação com a promoção do desenvolvimento sustentável por meio das suas inovações: Têm Açúcar?, VECZO, eBatuta e Bureo, dentre as empresas presentes no portfólio do programa.

A Tem Açúcar busca trazer de volta o sentimento de amizade entre as pessoas que moram próximas, por meio da sua plataforma que possibilita o empréstimo de objetos. A Veczo inova com o sistema de produto e serviço que oferece próteses ajustáveis de acordo com a necessidade das pessoas por meio de aluguel. A eBatuta cria um canal de encontro entre turistas que buscam comprar lembranças de viagens e artesões locais. Por fim a Bureo possui programas de recolhimento de redes de pesca dos oceanos, processando o material e transformando-os em produtos como skates e óculos.

Foi percebida a preocupação das empresas em abarcar as três dimensões do triple bottom line de Elkingotn (1997) no desenvolvimento dos seus produtos e serviços. Assim como foi possível identificar a maioria dos elementos do cubo da inovação sustentável de Hansen, Grosse-Dunker e Reichwald (2009) nas inovações mapeadas. Torna-se importante salientar a presença dos elementos integração dos critérios de sustentabilidade; sensibilização no contexto da sustentabilidade e marketing direcionado à inovação sustentável nas quatro empresas pesquisadas.

Ainda no que diz respeito aos resultados do cubo da inovação sustentável, foi possível perceber que os elementos referentes a integração dos stakeholders e ao incremento do sistema de produto e serviço precisam ser introduzidos ou melhor trabalhados na gestão estratégica das organizações, de maneira a possibilitar que as empresas possam desenvolver os seus produtos e serviços, gerando maiores benefícios ao meio ambiente e sociedade. Com os resultados encontrados, os autores entendem que o programa Startup Chile poderia intensificar a realização de eventos e trocas entre as empresas do seu portfólio com o objetivo de disseminar práticas que se fazem presentes entre as empresas identificadas neste estudo.

Torna-se importante salientar que as empresas analisadas já iniciarem os seus modelos de negócios levando em consideração a promoção da sustentabilidade, gerando benefícios para o econômico, ambiental e social. Isto demonstra que empresas pequenas também têm muito a contribuir com o futuro da qualidade do planeta, e exigindo também mais esforços das grandes corporações.

Como limitações deste estudo, têm-se a coleta de dados baseada apenas no website e reportagens sobre as empresas, no qual sugere-se o aprofundamento dos casos com entrevistas com os fundadores das startups para estudos futuros, visando também a possibilidade de abranger diferentes variáveis para análise. Sugere-se também a realização de estudos com o programa Startup Brasil, com a finalidade de se averiguar as práticas inovadoras para a sustentabilidade, das organizações do programa brasileiro. 


\section{Referências}

ALMEIDA, A. Análise da inovação sustentável aplicada às empresas da cadeia turística da Costa do Conde (PB). In: Seminário da Associação Nacional de Pesquisa e Pós-Graduação em Turismo, São Paulo/SP. Anais do Seminário da ANPTUR, 2015.

BARBIERI et al. Inovação e Sustentabilidade: Novos modelos e proposições. Revista de Administração Eletrônica, v.50, n.2, p.146-154, 2010.

BLANK, S; DORF, B. The Startup Owner's Manual: The Step-by-step Guide For Building a Great Company. K\&S Ranch, 2012.

BOS-BROUWERS, H. E. J. Corporate sustainability and innovation in SMEs: Evidence of themes and activities in practice. Business Strategy and the Environment, v. 19, n. 7, p. 417-435, 2010.

BUREO. Website da empresa. Disponível em: . < https://bureo.co/ > Acesso em: 04/05/2017.

CARLOMAGNO, M, M.; SCHERER, F, O. Gestão da inovação na prática: Como aplicar conceitos e ferramentas para alavancar a inovação. Porto Alegre: Atlas, 2009.

CUTOVOL, I. T. M. O programa piloto brasileiro para concessão das patentes verdes. Cadernos de Gestão e Empreendedorismo, v. 4, n. 3, p. 49-57, 2016.

DA SILVA et al. O perfil dos empreendedores nas startups: um estudo de caso na incubadora tecnológica de santa maria. Anais do $2^{\circ}$ Fórum Internacional Ecoinovar, Santa Maria/RS, 2013.

DIAS, R. Responsabilidade Social: fundamentos e gestão. São Paulo: Atlas, 2012.

EBATUTA. Website da empresa. Disponível em: . < http://www.ebatuta.com/ > Acesso em: 1/06/2017.

ELKINGTON, J. Canibais com garfo e faca. São Paulo: Makron Books, 1997.

EL DEFINIDO. Lazarus la protesis super moderna y hecha em Chile que sorprendera al mundo. Disponível em: .$<$ http://www.eldefinido.cl/actualidad/lideres/8262/Lazarus-la-protesis-super-moderna-y-hecha-en-Chile-quesorprendera-al-mundo/>. Acesso em 19/06/2017.

EPOCA NEGOCIOS. Site Têm Açúcar facilita empréstimos entre vizinhos. Disponível em: .< https://epocanegocios.globo.com/Informacao/Acao/noticia/2015/03/site-tem-acucar-facilita-emprestimosentre-vizinhos.html >. Acesso em: 20/06/2017

FIGUEIREDO, C. B.; FILHO, J. R. F. Sustentabilidade da Indústria de Petróleo. V Congresso Nacional de

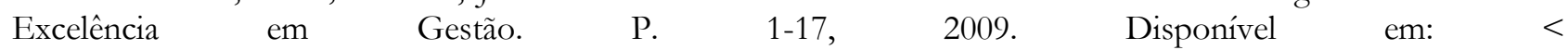
www.excelenciaemgestao.org/Portals/2/documents/cneg5/anais/T8_016 4_0800.pdf>. Acesso em: 04 de setembro de 2016.

GIMENEZ, C.; SIERRA, V.; RODON, J. Sustainable operations: Their impact on the triple bottom line, Int. J. Production Economics, v. 140, n. 1, p. 149-159, 2012.

GLOBAL ACELERATOR REPORT. Relatório de aceleração global. Acesso em: .< http://gust.com/pt/global-accelerator-report-2015/ >. Acesso em: 20/06/2018.

GODOY, A. S. Pesquisa qualitativa: tipos fundamentais. Revista de Administração de

Empresas - RAE. v.35, n.3, p. 20-29. 1995.

HANSEN, E; GROSSE-DINKER, F.; REICHWALD, R. Sustainability innovation cube: a framework to evaluate sustainability-oriented innovations. International Journal of Innovation Management, v. 13, n..4, p. 683-713, 2009.

HANSEN, E; GROSSE-DUNKER. Sustainability-Oriented Innovation. Encyclopedia of Corporate Social Responsibility, $\quad$ p. 2407- 2417, 2013.20 Disponível <https://link.springer.com/referenceworkentry/10.1007\%2F978-3-642-28036-8_552>. Acesso em 12/04/2017. 
KUHL et al. (2016). Colaboração para inovação e desempenho sustentável: evidências da relação na indústria eletroeletrônica. Brazilian Business Review, v.13, n.3, p. 1-25, 2016.

MACCHION, L. et al. Improving innovation performance through environmental practices in the fashion industry: the moderating effect of internationalisation and the influence of collaboration. Production Planning \& Control.

Disponível

http://www.tandfonline.com/doi/abs/10.1080/09537287.2016.1233361?journalCode=tppc20 Acesso em 26/10/2016.

MANDAKOVIC, V.; COHEN, B.; AMORÓS, J. E. Entrepreneurship Policy and Its

Impact on the Cultural Legitimacy for Entrepreneurship in a Developing Country Context. In: PERISORTIZ, M.; MERIGÓ-LINDAHL, J. M. Entrepreneurship, Regional Development and Culture, 2015.

MARTENS et al. Um estudo de inovação sustentável em projeto de desenvolvimento de produtos. Exacta, v. 14, n. 3, p. 477-494, 2016.

NIDUMOLU et al. Why Sustainability Is Now the Key Driver of Innovation. Harvard Business Review, p. 29, 2009.

PORTER, M. Estratégia Competitiva - Técnicas para análise de indústrias e da concorrência. Campus, 2004.

PORTER, M.; KRAMER, M. R. Strategy and society: the link between competitive advantage and corporate social responsibility. Harvard Business Review, v. 84, p. 78-92, 2006.

QUINTAIROS, P. C. R.; ALMEIDA, A. V. A.; OLIVEIRA, E. A. A. Q. Parques Tecnológicos com ênfase em tecnologia da informação e comunicação: um modelo para implementação no Vale do Paraíba Paulista. Latin American Journal of Business Management, v. 4, v. 1, p. 2-24, 2013.

RICHARDSON, R. J. Pesquisa social: métodos e técnicas. 3. ed. São Paulo: Atlas, 1999.

RIES, E.; A Startup Enxuta: Como os empreendedores atuais utilizam a inovação contínua para criar empresas extremamente bem-sucedidas. São Paulo: Lua de Papel, 2012.

SANTOS et al. Gestão Da Inovação Sustentável: Um Estudo de Caso em uma empresa de fertilizantes biológicos.

Revista Gestão e Desenvolvimento em contexto- Gedecon Edição Especial - IV Fórum De Sustentabilidade, v. 2, n.2, p. 133-148, 2014.

SANTOS, F. Ética Empresarial: Políticas de Responsabilidade Social em cinco dimensões: Sustentabilidade, Respeito à Multicultura, Aprendizado contínuo, Inovação e Governança Corporativa. São Paulo: Editora GEN/Atlas, 2015.

SANTOS, W. A. F.; BAPTISTA, J. A. A. Investimento das pequenas empresas no triple bottom line. REPAE Revista Ensino e Pesquisa em Administração e Engenharia, v. 2, n. 1, 109-120, 2016.

SANTOS, A.; SILVA, G. Organizações Inovadoras Sustentáveis: Insights em prol de maior competitividade. Revista Brasileira de Gestão e Inovação. v. 3, n. 3, p. 13-26, 2016.

SAVITZ, W., A. A empresa sustentável. Rio de Janeiro: Campus, 2007.

SEEDOBE, D.; JEANRENAUD, S.; BESSANT, J,. Managing innovation for sustainability. R\&D Management, v.42, n.3, p. 195-206, 2012.

SCHUMPETER, J. Teoria do desenvolvimento econômico: uma investigação sobre lucros, capital, crédito, juro e o ciclo econômico. São Paulo: Abril Cultural, 1982.

TEM AÇUCAR. Web site da empresa. Disponível em: . $<$ http://www.temacucar.com/ .> Acesso em: $17 / 06 / 2017$

THE SEDGE. Ebatuta the adventures of a moroccan traveler. Disponível em: .< https://www.thesedge.org/socent-spotlights/ebatuta-the-adventures-of-a-moroccan-traveler $>$. Acesso em: $\underline{21 / 06 / 2017}$

TRIFILOVA et al. Sustainability-driven innovation and the Climate Savers' programme: experience of international companies in China. Corporate Governance. v. 13, n. 5, p. 599-612, 2013. 
TRIVIÑOS, A. N. S. Introdução à pesquisa em ciências sociais: a pesquisa qualitativa em educação. São Paulo: Atlas, 1987

VARADARAJAN, R. Toward sustainability: public policy, global social innovations for base-of-the-pyramid markets, and demarketing for a better world. Journal of International Marketing, v. 22, n. 2, p. 1-20, 2014.

VECZO, Website da empresa. Disponível em: . < http://veczo.cl/cl/ > . Acesso em: 15/06/2018

VOLKMER, G. Aplicação de um modelo 3-D de sustentabilidade na análise de propriedades agroecológicas na área de influência de unidades de conservação no Rio Grande do Sul. Dissertação. Mestrado em Administração da Universidade Federal do Rio Grande do Sul, 2014. 